\title{
Presença de inibidores de proteases em amostras comerciais de "faseolaminas" utilizadas como bloqueadores de carboidratos e os riscos à saúde
}

\author{
Occurrence of proteases inhibitors in commercial samples of \\ "phaseolamins" used as carbohydrate blockers and the health risks
}

RIALA6/1564

Mariana dos Santos MURRA, Tassia Batista PESSATO, Olga Luisa TAVANO*

*Endereço para correspondência: Departamento de Nutrição, Instituto de Ciências da Saúde, Universidade Federal do Triângulo Mineiro, Rua Getulio Guaritá n 159, sala 323, Uberaba, MG, Brasil. CEP 38025-440, Tel./Fax: (34) 3318-5922, E-mail: tavanool@yahoo.com.br

Recebido: 31.01.2013 - Aceito para publicação: 02.09.2013

\section{RESUMO}

Foi investigada a veiculação de inibidores de proteases, concomitante ao consumo de "faseolamina", cuja ingestão diária e de maneira prolongada poderia estar associada ao risco no desenvolvimento de alterações morfológicas e metabólicas de pâncreas. Dez amostras foram obtidas em farmácias de manipulação no município de Uberaba - MG, as quais são comercializadas na forma de cápsulas como "faseolamina" e uma como "farinha de feijão branco", além de amostra de farinha preparada a partir da trituração de feijões brancos (Phaseolus vulgaris) obtidos comercialmente, sem qualquer processamento. Estas amostras foram analisadas efetuando-se a determinação de atividade de inibidores de tripsina, a determinação de proteínas totais e de atividade de inibição de amilase. Todas as amostras estudadas apresentaram atividades de inibição de tripsina, porém com baixa ou mesmo inexistente inibição de amilase; e em algumas amostras foi detectada concentração de proteínas muito inferior ao esperado. Uma vez observada a presença de atividade de inibição de tripsina em todas as amostras estudadas, e pela inexistência de níveis seguros de consumo estabelecidos para o ser humano, e ainda baseando-se nos trabalhos sobre associação de ingestão prolongada destes inibidores com alterações de atividade pancreática, o consumo destes "bloqueadores de carboidratos" deveria ser melhor controlado.

Palavras-chave. faseolamina, inibidores de proteases, inibidores de tripsina, bloqueadores de carboidratos, inibidores de amilase, pâncreas.

\begin{abstract}
This study aimed at verifying the risk in developing the metabolic and morphological changes in pancreas, owing to the use of daily and prolonged consumption of protease inhibitors in conjunction with "phaseolamine". Ten samples were obtained from drugstores in the city of Uberaba - MG, sold as "phaseolamine" and one known as "white bean flour", and also one flour sample produced from commercial white beans (Phaseolus vulgaris) without any processing. These samples were analyzed by determining the activity of trypsin inhibitors, the total protein and the amylase inhibition activity. Trypsin inhibition activity was found in all of analyzed samples; however, the amylase inhibition activity was low, and in some samples the protein concentration was much lower than expected. Seeing that the trypsin inhibitory activity was detected in all of analyzed samples, and considering that the prolonged ingestion of these inhibitors might cause activity changes in pancreas, the consumption of these types of "carbohydrate blockers" should be deeply discussed, since the safe amounts of these compounds have not been established for humans consumption yet.
\end{abstract}

Keywords. phaseolamine, protease inhibitors, trypsin inhibitors, starch blockers, amylase inhibitors, pancreas. 


\section{INTRODUÇÃO}

A obesidade, considerada uma doença crônica em que há acúmulo excessivo de tecido adiposo a ponto de comprometer a saúde do indivíduo, vem alcançando níveis alarmantes nas ultimas décadas em muitos países ${ }^{1,2}$. Considerando-se a maior causa do ganho de peso como um "desbalanço" entre a ingestão e o gasto de energia, e que carboidratos são as maiores fontes de calorias nas dietas, algumas ações a respeito poderiam ser consideradas, como a recomendação de consumo de alimentos com baixo índice glicêmico ou da ingestão de componentes que possam reduzir a digestão e consequente absorção dos carboidratos ${ }^{3}$. Entre a mistura de carboidratos normalmente presentes nas dietas, o amido costuma ser de grande representatividade, e o primeiro passo para liberação de glicose advinda desta molécula é a ação da alfaamilase, em especial a pancreática liberada no intestino. Desta forma, a inibição da alfa-amilase reduz a assimilação de carboidratos, com especial redução de picos de glicose pós-prandial, o que é particularmente importante no caso de pacientes diabéticos ${ }^{1,2}$. Diferentes inibidores de amilases estão disponíveis, seja na forma de medicamentos, como a Acarbose, ou seja, na forma de outros suplementos, como extratos vegetais, sendo que dentre eles estão os derivados de farinhas de feijão branco, que trariam em sua composição inibidores de alfa-amilase ${ }^{4,5}$.

Estes chamados "bloqueadores de carboidratos" ("carbohidrates blockers" ou "starch blockers"), embora se proponham a uma ação de grande importância e especial interesse a pacientes diabéticos, ainda geram muitas controvérsias, em especial no que se refere ao uso dos derivados de feijão branco. A faseolamina, uma proteína dos grãos, é a responsável por este efeito de inativação da $\alpha$-amilase, sendo possível sua obtenção comercial por meio de produtos diretamente identificados como "faseolamina" ou mesmo "farinha de feijão branco"

A utilização de faseolamina como auxiliar na inibição da absorção de carboidratos não é uma ideia recente. Na década 1980 houve grande consumo desses produtos comercializados como bloqueadores de carboidratos nos EUA, sendo que em julho de 1982 a FDA (Food and Drug Administration) interrompeu a distribuição de todos os inibidores de amilase até que se pudesse ter segurança sobre seus riscos e benefícios, quando estimava-se que em junho desse mesmo ano foram consumidas cerca de 10 milhões de cápsulas por semana neste país ${ }^{7}$. Desde então, a discussão sobre o uso de tais compostos gera controvérsias. Autores alertam para a possível ineficiência destes inibidores em relação à digestão de carboidratos em seres humanos, e mesmo para os riscos embutidos em seu consumo. Carlson et $\mathrm{al}^{7}$ estudando a ação de inibidores de amilase comercializados, sobre voluntários com idade entre 23 e 32 anos, não verificaram quaisquer alterações sobre parâmetros como glicose sanguínea ou insulina. Embora diversos estudos demonstrem a presença e atividade de proteínas com potencial para inibição de amilase, estes estudos encontraram em seus protocolos in vitro condições favoráveis para esta inibição, o que in vivo não seria facilmente reproduzido, já que estes compostos sofreriam ação do suco gástrico em sua passagem pelo estômago e a ação de proteases digestivas rapidamente reduziria seu potencial de ação sobre as amilases pancreáticas, e, por outro lado, feijões apresentam outros componentes antinutricionais e tóxicos que poderiam ser veiculados conjuntamente, como lectinas e inibidores de proteases ${ }^{8}$. Liener et $\mathrm{al}^{9}$, ainda na década 1980 , demonstraram a presença destes outros compostos em "bloqueadores de carboidratos" à base de farinha de feijão, comercializados nos Estados Unidos, alertando para os riscos da ingestão destes outros componentes, em especial os inibidores de proteases e, sobretudo, de maneira crônica.

Embora já se saiba que esta inibição ocorre com intensidades distintas entre tripsinas de espécies diferentes, como ratos, porcos, camundongos e seres humanos, alguns trabalhos demonstraram que a tripsina humana é também sensível à ação destes inibidores ${ }^{10-12}$, o que poderia desencadear um mecanismo de hiperestimulação da secreção pancreática com consequente surgimento de hipertrofia e/ou hiperplasia das células acinares do pâncreas ${ }^{13-16}$. Ainda que em animais este fenômeno já tenha sido demonstrado, poucos estudos têm sido diretamente realizados com humanos, mas alguns trabalhos já indicam que esta relação poderia ocorrer. Holm et a ${ }^{11}$ utilizando infusão de extrato de grãos crus de soja em 11 voluntários, por meio de sonda, verificaram uma inibição de $55 \%$ de atividade de tripsina durante a infusão. Friess et $\mathrm{al}^{17}$ realizaram um estudo com 20 voluntários, com idades entre 24 e 28 anos, que receberam uma espécie de inibidor de tripsina, o "Camostato", durante as refeições, e após duas semanas foi possível observar um aumento no tamanho das células acinares por exames de ultrassom.

Já no início do século XX, Osborne e Mendel observaram que era necessário submeter a soja a 
tratamento térmico para que esta pudesse ser utilizada como alimento sem causar prejuízos no desenvolvimento daquele organismo que a consumia, fato inicialmente observado em animais, e logo se demonstrou que a presença de certos componentes na soja interferia na absorção de suas proteínas, estabelecendo claramente uma relação inversa entre o conteúdo de inibidores de proteases presentes na soja e a digestibilidade de suas proteínas ${ }^{8,18,19}$.

A eficiente inativação térmica destes inibidores já foi demonstrada por inúmeros trabalhos ${ }^{20-26}$. Mas, infelizmente, embora o consumo habitual destes grãos seja predominantemente na forma cozida, há alguns fatos preocupantes, como a crescente inclusão destes "reguladores" de absorção de carboidratos, preparados com farinhas de feijões cujo processamento térmico não poderia ser intenso, de maneira a preservar a atividade de inibidores de amilase. Chokshi ${ }^{5}$ afirma que os produtos comercializados sob denominação de "faseolamina" isolada seriam farinhas de feijão branco que sofreram tratamento térmico controlado, ou seja, brando, o que permitiria que apenas a faseolamina, proteína inibidora de amilase, estivesse ativa, inativando-se os demais agentes tóxicos. Esta seria uma forma segura e desejável de consumo de inibidores de absorção de carboidratos.

Desta forma, este trabalho se propõe a analisar a presença de inibidores de proteases em amostras comerciais de "faseolamina" e "farinha de feijão branco", destinados à redução da absorção de carboidratos, e discutir os riscos de sua ingestão para o ser humano.

\section{MATERIAL E MÉTODOS}

\section{Amostras}

Após consulta a farmácias de manipulação e locais de comercialização de "produtos naturais" encontrados no município de Uberaba - MG, foram obtidas 10 diferentes amostras, de distintos fornecedores, comercializadas sob a denominação de "faseolamina" e uma amostra comercializada como "farinha de feijão branco", todas disponíveis em frascos contendo entre 30 e 60 cápsulas de $500 \mathrm{mg}$ cada. Para todas as amostras, as cápsulas foram abertas, pesadas e seus conteúdos homogeneizados para utilização nos ensaios. Também se utilizou amostra de farinha preparada a partir da trituração de grãos in natura de feijões brancos (Phaseolus vulgaris) obtidos comercialmente, sem qualquer processamento.

\section{Determinação da atividade de inibição de tripsina}

A determinação da atividade de inibição de tripsina das amostras foi realizada como descrito por Kakade et $\mathrm{al}^{27}$, utilizando-se BAPNA (Benzoil-DLarginina-p-nitroanilida) como substrato e tripsina de pâncreas bovino (Type I, 10.000 BAEE unidades/ mg proteína, Sigma). Convencionou-se que 1 (uma) unidade de tripsina (UT) seria equivalente ao aumento de cada 0,01 de absorvância para as leituras das amostras. As atividades de inibição das amostras foram expressas considerando-se ensaio sem inibição (ausência de extrato) como $100 \%$ de atividade, e a diferença entre as unidades de atividade determinadas para as amostras e aquela da enzima livre, como UIT (Unidades de Inibição de Tripsina), expressas por grama de amostra.

\section{Determinação da atividade de inibição da amilase}

Para determinação da atividade de inibição de amilase das amostras foi utilizada amilase pancreática suína (a-amilase Type VI, Sigma A 3176). As amostras passaram por processo de extração $(1: 20 \mathrm{~m} / \mathrm{v})$ utilizando-se tampão fosfato, $10 \mathrm{mM}, \mathrm{pH} \mathrm{7,2,} \mathrm{contendo}$ $150 \mathrm{mM}$ de $\mathrm{NaCl}$, como descrito por Mosca et $\mathrm{al}^{28} \mathrm{~A}$ determinação da atividade foi realizada utilizando-se solução de amido $1 \%$ em tampão fosfato de sódio $\mathrm{pH}$ 6,9, $20 \mathrm{mM}$, contendo $6,7 \mathrm{mM}$ de $\mathrm{NaCl}$. Para a reação $80 \mu \mathrm{L}$ de solução de enzima foram incubados com $45 \mu \mathrm{L}$ de extrato. Após 10 minutos a $37^{\circ} \mathrm{C}$ foram acrescentados $125 \mu \mathrm{L}$ de solução de substrato e novamente mantidos a $37^{\circ} \mathrm{C}$, por $20 \mathrm{~min}$. A reação foi interrompida pela adição de reagente contendo DNS (ácido dinitrosalicilico) e os tubos foram mantidos sob fervura por 5 minutos. Após adição de $4,5 \mathrm{~mL}$ de água destilada, as leituras foram realizadas a $540 \mathrm{~nm}$. Uma curva de referência de maltose foi utilizada para os cálculos. Foi definida 1 UA (Unidade de Atividade) como a quantidade de enzima capaz de liberar $1 \mu \mathrm{Mol}$ de maltose. As atividades de inibição das amostras foram expressas considerando-se ensaio sem inibição (ausência de extrato) como 100 \% de atividade, e a diferença entre as unidades de atividade determinadas para as amostras e aquela da enzima livre, como UIA (Unidades de Inibição de Amilase), expressas por grama de amostra.

\section{Determinação de proteínas nas amostras}

A determinação de proteínas nas amostras foi realizada pelo método de Kjeldahl ${ }^{29}$, utilizando-se o fator 6,25 para conversão do teor de nitrogênio em proteínas. 


\section{RESULTADOS}

$\mathrm{Na}$ Tabela 1 são apresentados os resultados para inibições das enzimas digestivas encontrados para as 11 diferentes amostras dos produtos comercializados como "bloqueadores de carboidratos", juntamente com o resultado encontrado para a amostra preparada de farinha de feijão branco não processado. Na Tabela 2 estão os resultados para concentração de proteínas nestas mesmas amostras.

Tabela 1. Atividades de inibição de enzimas digestivas em amostras de "faseolamina" e farinha de feijão branco

\begin{tabular}{ccc} 
Amostra $^{*}$ & \multicolumn{2}{c}{ Unidades de Inibição ${ }^{* *}$} \\
\cline { 2 - 3 } UIT/g & UIA/g \\
\hline 1 & $9.250,00 \pm 1,02$ & $31,81 \pm 0,29$ \\
2 & $1.840,00 \pm 5,11$ & $31,57 \pm 0,10$ \\
\hline 3 & $2.055,50 \pm 8,36$ & $5,58 \pm 0,29$ \\
\hline 4 & $1.707,90 \pm 11,20$ & $6,16 \pm 0,16$ \\
\hline 5 & $1.623,76 \pm 0,50$ & $5,38 \pm 0,44$ \\
6 & $1.331,73 \pm 6,57$ & $6,42 \pm 0,51$ \\
\hline 7 & $1.257,43 \pm 14,40$ & $32,58 \pm 0,22$ \\
8 & $2.487,62 \pm 6,01$ & $4,98 \pm 0,62$ \\
\hline 9 & $600,00 \pm 8,83$ & $\mathrm{ND}$ \\
\hline 10 & $1.444,40 \pm 4,57$ & $6,12 \pm 0,89$ \\
\hline 11 & $10.062,50 \pm 3,78$ & $32,49 \pm 0,07$ \\
\hline 12 & $9.060,00 \pm 8,84$ & $32,94 \pm 0,18$ \\
\hline
\end{tabular}

* Amostras 1 a 10 comercializadas como "faseolamina"; amostra 11 comercializada como farinha de feijão branco; amostra 12 farinha produzida a partir de feijões brancos triturados, sem qualquer tratamento térmico. ${ }^{*}$ UIT $=$ Unidades de Inibição de Tripsina; UIA = Unidades de Inibição de amilase; *** $\mathrm{ND}=$ não detectada

Tabela 2. Concentração de proteínas de amostras de "faseolamina" e farinha de feijão branco

\begin{tabular}{cc} 
Amostra $^{*}$ & $\begin{array}{c}\text { Proteínas Totais } \\
(\mathrm{g} / \mathbf{1 0 0} \text { g de amostra })\end{array}$ \\
\hline 1 & 19,59 \\
2 & 18,72 \\
3 & 6,24 \\
4 & 2,59 \\
5 & 3,23 \\
6 & 3,66 \\
\hline 7 & 13,78 \\
8 & 4,73 \\
9 & 3,23 \\
10 & 4,52 \\
11 & 21,48 \\
12 & 22,34 \\
\hline
\end{tabular}

* Amostras 1 a 10 comercializadas como "faseolamina"; amostra 11 comercializada como farinha de feijão branco; amostra 12 farinha produzida a partir de feijões brancos triturados, sem qualquer tratamento térmico
De acordo com os dados apresentados na Tabela 1 é possível verificar que todas as amostras estudadas apresentavam atividades de inibição de tripsina.

A amostra 1, ainda que comercializada sob a denominação de "faseolamina", apresentou perfil muito semelhante ao encontrado para as amostras 11 e 12, representando amostras de farinhas de feijão branco, comercial e preparada, respectivamente, tanto no que se refere à atividade de inibição de tripsina detectada, como à atividade de inibição de amilase e percentual de proteínas (Tabelas 1 e 2).

As amostras 3 a 6 e 8 a 10 apresentaram atividades de inibição de amilase inferiores àquelas apresentadas pelas farinhas de feijão branco (amostras 11 e 12), sendo que a 9 não apresentou atividade detectável. Também estas mesmas amostras apresentaram percentuais de proteínas abaixo dos encontrados para as amostras de farinha.

Nenhuma das amostras comercializadas como faseolamina apresentou percentuais de proteínas ou atividade de inibição de amilase em valores superiores aos apresentados pelas farinhas, como se esperava. Como anteriormente descrito, "faseolamina" seria a denominação para a fração protéica dos grãos de feijão branco responsável pela inibição da $\alpha$-amilase digestiva. A comercialização de um produto sob tal denominação poderia induzir à ideia da obtenção de um produto composto por isolado protéico, e, portanto, de alta concentração de proteínas, o que não foi observado para nenhuma das amostras aqui estudadas (Tabela 2). Ainda poderia-se esperar que, de acordo com o originalmente proposto e discutido por Chokshi ${ }^{5}$, os produtos comercializados como "faseolamina" fossem então sinônimo de farinhas de feijão branco que sofreram tratamento térmico controlado, ou seja, produtos com alta atividade de inibição de amilase, comparável às farinhas originárias do produto, mas com ausente atividade de outros compostos tóxicos, como os inibidores de proteases, o que tampouco foi verdadeiro para as amostras comerciais de "faseolamina" analisadas. Apenas as amostras 2 e 7 poderiam estar mais próximas a este conceito, uma vez que manteve atividade de inibição de $\alpha$-amilase próxima àquela da farinha de feijão branco preparada, mas, ainda que com a redução da atividade de inibição da tripsina, esta também continuou presente nesta amostra (Tabela 1). Porém na amostra 7 , ao observarmos sua diluída concentração de proteínas (Tabela 2) em comparação à amostra 12, não parece ser 
composta de material advindo somente de farinha de feijão branco. Vale lembrar, que ainda que a amostra seja comercializada como "farinha de feijão branco", como a 11, esta deveria garantir a inativação dos inibidores de proteases, o que não se verifica pelos dados da Tabela 1 .

A amostra 9, particularmente, além de comercializada como "faseolamina" e, de acordo com informações do fabricante, ser um "extrato isolado de feijão branco", o que sugere claramente uma forma isolada e que deveria, portanto, apresentar alta atividade de inibição de amilase, ao contrário do esperado, não foi encontrada nenhuma atividade inibitória detectável (Tabela 1). A amostra 1, embora se apresentou sob a denominação de "faseolamina", tinha concentração de proteínas e atividades de inibidores que se assemelhavam à amostra 12, sugerindo que poderiam ser diretamente uma amostra de farinha de feijão branco sendo comercializada. Pires et $\mathrm{al}^{30}$, ao estudarem a composição dos diferentes tipos de feijão, observaram valores próximos aos encontrados neste trabalho, apresentando dados que variaram entre 21,97 e 25,93 \% de proteína. Embora a amostra 2 tenha apresentado valores menores de UIT, seus demais resultados também sugerem que seja farinha de feijão branco. Os baixos teores de proteínas das amostras, em especial das amostras 4 a 6 e 8 a 10 (Tabela 1), levantam dúvidas sobre a qualidade destes produtos comercializados. Estas amostras apresentaram resultados que sugerem baixa eficiência para sua proposta de inibição de absorção de carboidratos, de acordo com suas baixas atividades de inibição de $\alpha$-amilase, mas apresentam atividade de inibidores de tripsina, sugerindo concomitantemente risco associado a seu consumo em função desta exposição diária a inibidores de proteases.

\section{DISCUSSÃO}

Embora os resultados de inibição de tripsina aqui encontrados não sejam tão altos quanto os observados para leguminosas como a soja, estes resultados se aproximam dos encontrados em outros trabalhos e que apontam para a correlação positiva entre a atividade de inibição tripsina (UIT) nas dietas e desenvolvimento de patologias em animais. Em um estudo com ratos que foram alimentados por 14 dias com dieta à base de grão de bico não tratado termicamente, leguminosa esta também com baixo nível de UIT, observou-se o desenvolvimento de aumento do peso dos pâncreas (cerca de 47 \% de aumento, em relação aos animais alimentados com dieta à base da mesma farinha tratada termicamente) o que indicava o surgimento de hiperplasia e/ou hipertrofia dos órgãos ${ }^{31}$. De acordo com o observado no citado trabalho, os animais haviam consumido dieta com cerca de $3.000 \mathrm{UIT} / \mathrm{g}$, ou seja, supõe-se que as amostras da farinha de feijão branco cru, por apresentarem quantidades superiores de UIT/g amostra (Tabela 1), também poderiam elevar o risco de aumento na produção da tripsina e, consequentemente, alteração do órgão como o observado para os animais, e mesmo as amostras de "faseolamina" aqui estudadas, que apresentaram em média $50 \%$ desta atividade de inibição de tripsina, devem ser consideradas com grande atenção.

Como anteriormente já citado, a ingestão, em especial de maneira prolongada ${ }^{32}$, deste tipo de composto, poderia alimentar o sistema de feedback referente à ação da colecistoquinina, desencadeando uma hiperestimulação da atividade pancreática, associada ao desenvolvimento de hiperplasia e hipertrofia das células do pâncreas. Estudos apontam que este tipo de fenômeno, quando ocorrido em pessoas com alterações iniciais das células acinares, poderia contribuir para a aceleração de processos de desenvolvimento de câncer pancreático ${ }^{13,33,34}$.

Os mecanismos de indução da hiperplasia e hipertrofia pancreática começaram a ser esclarecidos a partir de 1972, quando Green e Lyman ${ }^{35}$ demonstraram que a remoção do suco pancreático e bile do intestino causava aumento na secreção de enzimas digestivas, o que era revertido quando tripsina e quimotripsina eram injetadas por canulação diretamente no duodeno. Desde então diferentes hipóteses foram levantadas para a explicação do mecanismo de resposta e regulação da secreção pancreática. Um dos mecanismos mais discutidos é aquele que envolve a regulação do feedback da secreção pancreática das enzimas digestivas pela ação da colecistoquinina (CKK), um hormônio ao qual se atribui a mediação desta secreção pancreática, além de apresentar envolvimento em outras funções, como a motilidade gástrica e produção da sensação de saciedade, embora muitas dúvidas ainda pairem sobre como exatamente esta regulação ocorre e quais os fatores que a influenciam ${ }^{36-39}$. Diversos estudos convergem em demonstrar alguns pontos destas vias, cujo esquema geral foi representado na Figura 1.

A colecistoquinina, presente nas células endócrinas proximais do intestino delgado, é liberada no sangue assim que há estimulo pela chegada de componentes da dieta ou quando recebem um sinal de que a atividade de tripsina e/ou quimotripsina estão 


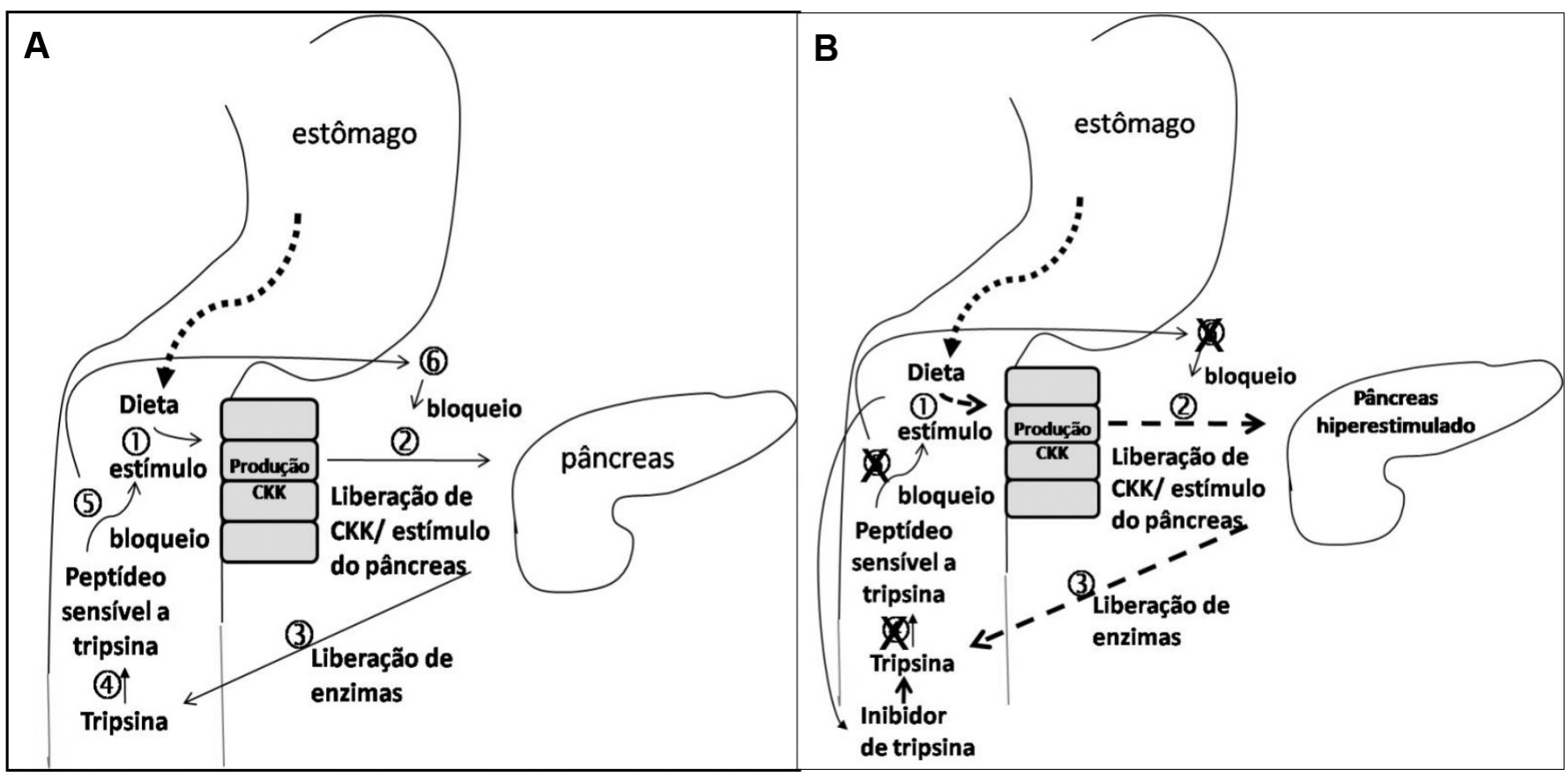

Figura 1. Esquema de produção de hiperestímulo pancreático através da presença de inibidores de tripsina na dieta. A) Mecanismo fisiológico normal de estímulo pancreático (1-Sinal de produção de colecistoquinina (CKK) pela proteína da dieta, 2- Liberação de CKK, 3- Liberação de tripsina, 4- Alta concentração de tripsina na luz intestinal liberando peptídeos bloqueadores, 5- Peptídeos inibindo o sinal de produção de CKK e 6- bloqueio da liberação de CKK e do estímulo de produção pancreática de tripsina); B) Mecanismo fisiológico alterado pela ingestão de inibidores de tripsina, onde as etapas 4, 5 e 6 ficam anuladas, e o bloqueio do estimulo de produção enzimática não ocorre, provocando estimulação constante e hiperprodução pancreática

diminuindo no lúmen intestinal e ainda há proteínas da dieta a serem digeridas ${ }^{37,38}$. Embora ainda carente de alguns esclarecimentos, esta sinalização acredita-se ser realizada por um peptídeo sensível à tripsina, que seria o responsável por transformar esta queda na concentração de tripsina e quimotripsina em um sinal que regulasse a liberação de CKK. Uma vez que haja liberação de CKK no sangue, e por haverem receptores de membrana para CKK nas células acinares do pâncreas, este então é estimulado a produzir e secretar mais suco pancreático, contendo então a tripsina entre seus componentes enzimáticos. O novo aumento da atividade de tripsina no lúmen intestinal acaba então por exercer um feedback negativo na liberação de CKK, que diminui, até que nova redução na concentração de tripsina volte a lhe estimular ${ }^{37-40}$.

A partir da compreensão deste mecanismo pode-se então supor que todo fenômeno que cause a redução da atividade de tripsina no lúmen intestinal durante processos de digestão pode levar a uma super estimulação da produção de CKK e, consequentemente, uma super estimulação pancreática, que seria responsável pelo surgimento de hiperplasia/hipertrofia pancreática na ocasião da ingestão continuada de dietas contendo inibidores de tripsina em sua composição ${ }^{16,34}$.

A carcinogenese pancreática se inicia com o surgimento de células acinares atípicas ${ }^{41}$. Estudos realizados com modelos animais, em que ratos tiveram a indução inicial de câncer quimicamente com azazerina, demonstram que aqueles animais que recebiam dietas a base de soja crua apresentavam aumento de tamanho e número destas células muito mais acelerado do que aqueles que não recebiam a dieta ${ }^{16}$. Desta forma, sugerese uma associação entre o desenvolvimento de hiperplasia e/ou hipertrofia pancreática e aumento de risco de câncer de pâncreas.

Alguns autores chamam a atenção ao relatarem que em ensaios realizados com a tripsina humana foi encontrada uma menor atividade de inibição do que aquelas observadas para tripsinas de outras espécies ${ }^{10,42}$. Em ensaio realizado por Nit e Plahar ${ }^{43}$, por exemplo, com feijão do tipo Caupi, observou-se que o extrato bruto da amostra inibiu significantemente mais a tripsina bovina, quando comparada sua atividade com a tripsina humana, 
mas, houve inibição de cerca de $45 \%$, o que indica riscos do consumo por parte de seres humanos destes produtos não processados termicamente.

Quantidades de inibidores de proteases seguras para o consumo humano ainda não foram estabelecidas. Neste trabalho, cada cápsula comercializada continha em média $500 \mathrm{mg}$ de produto, e a recomendação de consumo era equivalente a 1 cápsula por grande refeição (almoço e jantar), ou seja, em média 2 cápsulas por dia (cerca de 1 grama de produto, segundo as informações de rótulos), o que acaba por expor o indivíduo a quantidades não controladas e que poderiam significar risco à saúde. Estes dados sugerem uma necessidade urgente de discussão sobre o consumo não controlado de tais produtos e que se estabeleçam níveis seguros para o consumo.

\section{CONCLUSÃO}

Foi possível observar neste estudo, a presença de atividade de inibição de tripsina em todas as amostras comercializadas como "faseolamina" e "farinha de feijão branco". Os baixos resultados de atividade de inibição de amilase e teores de proteínas nas amostras estudadas colocam em dúvida a qualidade e a eficiência destes produtos. Considerando que até o momento não existem trabalhos que estabeleçam níveis seguros de consumo destes compostos para o ser humano, e, diante dos citados relatos na literatura que associam a ingestão prolongada destes inibidores com alterações da atividade pancreática, levando assim ao aumento do risco de desenvolvimento do câncer pancreático, concluímos que o consumo destes tipos de "bloqueadores de carboidratos" deveriam ser bem mais ponderados e fiscalizados pelos orgãos competentes.

\section{AGRADECIMENTOS}

Os autores agradecem à Profa Dra. Roseli Aparecida da Silva Gomes, pela disponibilização de recursos do Laboratório de Bioquímica e Biofísica/ICBN/UFTM e a Christopher Mosley pela revisão dos textos em inglês.

\section{REFERÊNCIAS}

1. Ferreira VA, Magalhães, R. Obesidade no Brasil: tendências atuais. Rev Port Saúde Publ. 2006; 24(2):71-81.

2. Ryan DH, Kushner R. The State of Obesity and Obesity Research. JAMA. 2010;304(16):1835-6.

3. Steyer TE, Ables A. Complementary and alternative therapies forweight loss. Prim Care Clin Office Pract. 2009; 36: 395-406.
4. Udani JK, Singh BB, Barrett ML, Preuss HG. Lowering the glycemic index of white bread using a white bean extract. Nutr J. 2009;8(52):1-5.

5. Chokshi D. Subchronic oral toxicity of a standardized white kidney bean (Phaseolus vulgaris) extract in rats. Food Chem Toxicol. 2007;45:32-40.

6. Marshall JJ, Lauda CM. Purification and Properties of Phaseolamin, an Inhibitor of a-Amylase, from the Kidney Bean (Phaseolus vulgaris). J Biol Chem.1975;250(20):8030-7.

7. Carlson GL, Li BUK, Bass P, Olsen WA. A Bean $\alpha$-Amylase Inhibitor Formulation (Starch Blocker) Is Ineffective in Man. Science.1983;219:393-5.

8. Liener, IE. Toxic constituents of plants foods. $2^{\text {a }}$ ed. New York: Academic Press; 1980.

9. Liener IE, Donatucci DA, Tarcza JC. Starch blockers: a potential source of trypsin inhibitors and lectin. Am J Clin Nutr.1984; 39:196-200.

10. Deglaire A, Moughan PJ, Bos C, Tome D. Commercial Phaseolus vulgaris Extract (Starch Stopper) Increases Ileal Endogenous Amino Acid and Crude Protein Losses in the Growing Rat. J Agric Food Chem.2006;54:5197-202.

11. Holm H, Krogdahl A, Hansen LE. High and Low Inhibitor Soybean Meals Affect Human Duodenal Proteinase Activity Differently: In Vitro Comparison of Proteinase Inhibition. J Nutr.1998;118:521-5.

12. Reseland JE, Holm H, Jacobsen MB, Jenssen TG, Hanssen LE. Proteinase inhibitors induce selective stimulation of human trypsin and chymotrypsin secretion. J Nutr.1996;126(3):634-42.

13. Liener IE. Possible adverse effects of soybean anticarcinogens. J Nutr.1995;125(3):S:744-9.

14. Liener IE. Soybean protease inhibitors and pancreatic carcinogenesis. J Nutr.1996;126(2):582-3.

15. Liener IE. Trypsin inhibitors: concern of human nutrition or not? J Nutr.1986; 116(5):920-3.

16. Roebuck BD. Trypsin inhibitors: potential concern for humans? J Nutr.1987;117(2):398-400.

17. Friess H, Kleeff J, Isenmann R, Malfertheiner P, Büchler MW. Adaptation of the Human Pancreas to Inhibition of Luminal Proteolytic Activity. Gastroenterol.1998;115(2):388-96.

18. Durigan JF, Sgarbieri,VC, Bulisani EA. Protein value of dry bean cultivars; factors interfering with biological utilization. J Agric Food Chem.1987;2(35):694-8.

19. Silva MR, Silva MAAP. Fatores antinutricionais: inibidores de proteases e lectinas. Rev Nutr.2000;13(1):3-9.

20. Al-Wesali M, Lambert N, Welham T, Domoney C. The influence of pea seed trypsin inhibitors on the in vitro digestibility of casein. J Sci Food Agric.1995;68(4):431-7.

21. Antunes PL, Sgarbieri VC. Effect of heat treatment on the toxicity value of dry bean (Phaseolus vulgaris var. Rosinha G2) proteins. J Agric Food Chem.1980;28(5):935-8.

22. Egbe IA, Akinyele IO. Effect of cooking on the antinutritional factors of lima beans (Phaseolus lunatus). Food Chem.1990;35:81-7.

23. Khattab RY, Arntfield SD. Nutritional quality of legume seeds as affected by some physical treatments 2 . Antinutritional factors. Food Sci Technol.2009;42:1113-8. 
24. Mulimani VH, Paramjyothi S. Effect of heat and u.v. on trypsin and chymotrypsin inhibitor activities in redgram (Cajanus cajan NCAL.). J Food Sci Technol.1993;30(1):62-3.

25. Shimelis EA, Rakshit SK. Effect of processing on antinutrients and in vitro protein digestibility of kidney bean (Phaseolus vulgaris L.) varieties grown in East África. Food Chem.2007;103:161-72.

26. Wang N, Hatcher DW, Tyler RT, Toews R, Gawalko EJ. Effect of cooking on the composition of beans (Phaseolus vulgaris L.) and chickpeas (Cicer arietinum L.). Food Res Int.2010;43:589-94.

27. Kakade ML, Rackis JJ, Mcghee JE, Puski G. Determination of trypsin inhibitor activity of soy products: a collaborative analysis of an improved procedure. Am Assoc Cereal Chem.1974;51:376-82.

28. Mosca M, Boniglia C, Carrat B, Giammarioli S, Nera V, Sanzini E. Determination of a-amylase inhibitor activity of phaseolamin from kidney bean (Phaseolus vulgaris) in dietary supplements by HPAEC-PAD. Anal Chim Acta.2008;617:192-5.

29. Association of Analytical Communities - AOAC. Official Methods of Analysis. 15th ed. Arlington, VA, 1990

30. Pires CV, Oliveira MGA, Cruz GADR, Mendes FQ, Rezende ST, Moreira MA. Composição físico-química de diferentes cultivares de feijão (Phaseolus vulgaris L.). Alim Nutr.2005;16(2):157-62.

31. Tavano OL, Silva Junior SI, Demonte A, Neves VA. Pancreatic hypertrophy in rats caused by chickpea (Cicer arietinum L.) protein intake. Alim Nutr.2005;16(1):5-10.

32. Gumbmann MR, Dugan GM, Spangler WL, Baker EC, Rackis JJ Pancreatic response in rats and mice to trypsin inhibitors from soy and potato after short- and long-term dietary exposure. J Nutr.1989;119(11):1598-607.
33. Mills PK, Beeson WL, Abbey DE, Fraser GE, Phillips RL. Dietary Habits and Past Medical History as Related to Fatal Pancreas Cancer Risk Among Adventists. Cancer.1988;61:2578-85.

34. Roebuck BD, Kaplita PV, Edwards BR, Praissman M. Effects of Dietary Fats and Soybean Protein on Azaserine-induced Pancreatic Carcinogenesis and Plasma Cholecystokinin in the Rat. Cancer Res.1987;1(47):1333-8.

35. Green GM, Lyman RL. Feedback regulation of pancreatic enzyme secretion as a mechanism for trypsin induced hypersecretion in the rat. Proc Soc Exp Biol Med.1972;140:6-12.

36. Fushiki T, Iwai K. Two hypotheses on the feedback regulation of pancreatic enzyme secretion. Faseb J.1989;3:121-6.

37. Gride JR. Role of Cholecystokinin in the Regulation of Gastrointestinal Motility. J Nutr.1994;124(8):S:1334-9.

38. Owyang C. Negative Feedback Control of Exocrine Pancreatic Secretion: Role of Cholecystokinin and Cholinergic Pathway. J Nutr.1994;124(8):S:1321-6.

39. Reidelberger RD. Cholecystokinin and Control of Food Intake. J Nutr.1994;124(8):S:1327-33.

40. Liddle RA. Regulation of Cholecystokinin Synthesis and Secretion in Rat Intestine. J Nutr.1994;124(8):S:1308-14.

41. Shrikhande SV, Barreto G, Koliopanos A. Pancreatic carcinogenesis: The impact of chronic pancreatitis and its clinical relevance. Indian J Cancer.2009;46(4):288-96.

42. Weder JK, Kahleyss R. Reaction of lentil trypsin-chymotrypsin inhibitors with human and bovine proteinases. J Agric Food Chem.2003;51(27):8045-50.

43. Nit, CA, Plahar WA. Cowpea Inhibition of human and bovine protease activities and the effects of processing. Food Control.1996;7(3):129-33. 